\title{
Diagrams of entropy for ammonia-water mixtures: Applications to absorption refrigeration systems
}

\author{
Diovana Aparecida dos Santos Napoleao ${ }^{a, *}$, Jose Luz Silveira ${ }^{b}$, \\ Giorgio Eugenio Oscare Giacaglia ${ }^{c}$, Wendell de Queiroz Lamas ${ }^{a, b}$, \\ Fernando Henrique Mayworm Araujo ${ }^{b}$ \\ a Department of Basic and Environmental Sciences, School of Engineering at Lorena, University of Sao Paulo, Lorena, SP, Brazil \\ b Institute of Bioenergy Research, IPBEN-UNESP, Associated Laboratory of Guaratingueta, Sao Paulo State University, \\ Guaratingueta, SP, Brazil \\ c Post-graduate Programme in Mechanical Engineering, Department of Mechanical Engineering, University of Taubate, Taubate, SP, Brazil
}

\section{A R T I C L E I N F O}

\section{Article history:}

Received 31 October 2016

Received in revised form 1 June

2017

Accepted 26 June 2017

Available online 30 June 2017

Keywords:

Absorption refrigeration system

(ARS)

Ammonia-water mixtures

Entropy diagrams

Thermodynamic properties

\begin{abstract}
A B S T R A C T
The objective of this work is to calculate the entropy of ammonia-water mixture as a function of temperature, pressure, concentration, and other thermodynamic properties associated to absorption process, to support energy and exergy analysis of absorption refrigeration systems. This calculation is possible because a novel mathematical modelling was developed for this attempt. This determination will allow simulation and optimisation of absorption refrigeration systems, giving major importance in determining the values of thermodynamic properties of ammonia-water mixtures, such as enthalpy and entropy. A mathematical modelling for thermodynamics properties calculation at liquid and vapour phases of ammoniawater system is developed. The studies were based on the enthalpy vs. concentration diagram obtaining the enthalpy in the liquid phase corresponding at a temperature range from 80 ${ }^{\circ} \mathrm{C}$ to $-40{ }^{\circ} \mathrm{C}$. The mixtures enthalpy values were calculated for ammonia $\left(\mathrm{h}_{1 \mathrm{c}}\right)$ and water $\left(\mathrm{h}_{2 \mathrm{c}}\right)$ by using a non-linear regression program. The evaluation of thermodynamic properties in this work was discretised by formulating appropriate equations for each type of substance. However, thermodynamic properties of mixtures can be determined based on data from simple substances and mixing laws, or from an equation of state that considers the mixture concentration. The consistency of experimental data indicates the most suitable method to be used in entropy calculation.
\end{abstract}

(C) 2017 Elsevier Ltd and IIR. All rights reserved.

\section{Diagrammes entropiques pour des mélanges ammoniac-eau : applications aux systèmes frigorifiques à absorption}

Mots clés : Système frigorifique à absorption ; (ARS) ; Mélanges ammoniac-eau ; Diagrammes entropiques ; Propriétés thermodynamiques

\footnotetext{
* Corresponding author. Department of Basic and Environmental Sciences, School of Engineering at Lorena, University of Sao Paulo, Estrada Municipal do Campinho, s/n, 12602-810, Lorena, SP, Brazil.

E-mail address: diovana@usp.br (D.A.d.S. Napoleao).

http://dx.doi.org/10.1016/j.ijrefrig.2017.06.030

0140-7007/@ 2017 Elsevier Ltd and IIR. All rights reserved.
} 


\begin{tabular}{|c|c|}
\hline \multicolumn{2}{|l|}{ Nomenclature } \\
\hline$\alpha=\beta=A=B$ & Constants of mixture compounds \\
\hline \multicolumn{2}{|c|}{$=\mathrm{C}=\mathrm{D}=\mathrm{a}=\mathrm{b}$} \\
\hline$\Lambda_{\mathrm{ij}}=\Lambda_{\mathrm{ji}}$ & $\begin{array}{l}\text { Adjustable binary interaction parameters } \\
\text { of Wilson's equation }\end{array}$ \\
\hline $\mathrm{Cp}$ & Specific heat capacity $[\mathrm{kJ} / \mathrm{kg} . \mathrm{K}]$ \\
\hline $\mathrm{F}$ & Objective function \\
\hline G & Gibbs free energy $[\mathrm{kJ} / \mathrm{kg}]$ \\
\hline $\mathrm{M}_{\text {CALC. }}$ & Predicted values \\
\hline $\mathrm{M}_{\mathrm{EXP}}$ & Property experimental value \\
\hline $\mathrm{P}$ & Pressure $[\mathrm{MPa}]$ \\
\hline $\mathrm{R}$ & Universal constant of ideal gas [kJ/kmol.K] \\
\hline $\mathrm{T}$ & Temperature [K] \\
\hline $\mathrm{V}$ & Volume $\left[\mathrm{m}^{3}\right]$ \\
\hline $\mathrm{h}$ & Specific enthalpy $[\mathrm{kJ} / \mathrm{kg}]$ \\
\hline $\mathrm{s}$ & Specific entropy [kJ/kg.K] \\
\hline $\mathrm{x}$ & Ammonia concentration $\left[\mathrm{kg}_{\text {ammonia }} / \mathrm{kg}_{\text {mixture }}\right]$ \\
\hline \multicolumn{2}{|l|}{ Superscript } \\
\hline E & excess \\
\hline g & Vapour phase \\
\hline
\end{tabular}

$\begin{array}{ll}1 & \text { Liquid phase } \\ 0 & \text { Ideal gas state }\end{array}$

Subscript

$0 \quad$ Values of reference in vapour phase

1c Value calculated for ammonia

2c Value calculated for water

A Absorber

C Critical value

G Generator

MIXT. Mixture

MIXT.IDEAL Ideal mixture

MIXT.ACTUAL Actual mixture

i Related to ammonia

j Related to water

- Ideal gas state

$\mathrm{r} \quad$ Reduced thermodynamic properties

\section{Introduction}

Advances in absorption technology have motivated the development of this work. A frustrating aspect of this study is the lack of fundamentally systematic and detailed analysis of absorption technology, which is often omitted in the scientific literature.

In Alefeld and Radermacher (1994), related positive aspects of this issue have been addressed, adducing its inter-disciplinary nature, and showing the need of works combining different scientific areas, such as physics, chemical engineering, and mechanical engineering.

Contributions from different fields give us a better understanding of absorption technology, such as the following: physics comprising a wide spectrum; chemical engineering including chemical corrosion and physical-chemistry; and mechanical engineering considering heat and mass transfer, fluid dynamics, materials science, and applied thermodynamics.

However, in recent years, the development of absorption technology presented variations; in particular, the industry increased activities with manufactured products, resulting in this sector's improvement through research and development, with a lot of interest shown in this matter, which is actually confirmed by scientific publications in absorption refrigeration system (ARS) area monitoring.

In Seyfouri and Ameri (2012), several configurations of integrated refrigeration system consisting of a compression chiller and an absorption chiller powered by a micro-turbine to generate cooling at low temperatures were analysed.

The absorption technology, mainly in air conditioning systems, is adopted with preferential use of a binary solution consisting of water and lithium bromide (imported solution). However, the most common cooling system uses ammonia as refrigerant and water as absorbent. This solution is manufactured and used in Brazil.
The absorption machines have the advantage of using thermal energy instead of electricity, which today has become more expensive, especially in the context of the lack of investments in the national power supply.

The absorption facilities also allow recovering the heat lost in case of turbines and other types of facilities, which operate based on co-generation. Along with these advantages, the absorption machines are characterised by their simplicity, since there are no internal moving parts (pumps placed apart), which guarantees a silent and vibration-free operation.

In the absorption system, employing water and ammonia is one of the most reported in the literature, considering the data of enthalpy tables and diagrams according to concentration; however the entropy has not been given the same attention, due to the absence of corresponding data of this thermodynamic property, hitherto available in the literature, making a broader and more detailed study on the thermodynamics of this system necessary, in order to determine the exact interrelationship of entropy correlated with other properties.

Configurations, main thermodynamic and hydraulic parameters, and some design guidelines and operating experiences of a medium-temperature, ammonia-water-based compression/ re-absorption heat recovery system for district domestic hot water production were presented by Minea and Chiriac (2006). The critical point of the ammonia-water mixture was calculated directly from the Helmholtz free energy formulation by Akasaka (2009), in order to obtain simple correlations for the critical temperature, pressure, and molar volume for a given composition. A parametric analysis of a combined power/ cooling cycle, which combines the Rankine and absorption refrigeration cycles, uses ammonia-water mixture as the working fluid and produces power and cooling simultaneously, was presented by Vasquez Padilla et al. (2010).

A set of five equations describing vapour-liquid equilibrium properties of the ammonia-water system was presented by Patek and Klomfar (1995). Four of different correlations for 
the thermodynamic properties of ammonia-water mixtures used in studies of ammonia-water mixture cycles described in the literature were compared by Thorin et al. (1998). A theoretically based crossover model, which incorporates a crossover from singular thermodynamic behaviour at the critical point to regular thermodynamic behaviour far apart from the critical point, was presented by Edison and Sengers (1999) for the thermodynamic properties of ammonia. A new method for thermodynamic properties computations at high temperatures and pressures using Gibbs free energy and empirical equations for bubble and dew point temperature to calculate phase equilibrium was presented by Xu and Yogi Goswami (1999).

Modelling of the thermodynamic properties of ammoniawater refrigerant mixture was developed by Mejbri and Bellagi (2006).

The objective of this work is to calculate the entropy of ammonia-water mixture as a function of temperature, pressure, concentration, and other thermodynamic properties associated to absorption process, to support energy and exergy analysis of absorption refrigeration systems. This calculation is possible because a novel mathematical modelling was developed for this attempt. This determination will allow simulation and optimisation of absorption refrigeration systems, giving major importance in determining the values of thermodynamic properties of ammonia-water mixtures, such as enthalpy and entropy.

\section{Fundamentals of absorption refrigeration system}

The basic principle of a refrigeration system is to transfer heat from a low temperature reservoir to a high temperature reservoir that can be the environment (Silva, 1994).

The absorption diagram shown in Fig. 1 is based on the fact that the vapours of some refrigerants can be absorbed in large quantities by certain liquids or saline solutions. The refrigerant can be separated from the solution resulting from the absorption by heating. Thus, the absorption cycle replaces the compressor with the generator-absorber assembly and pump, while the evaporator, condenser, and the expansion valve operate in the same way as in the compression cycle.

In a continuous operating system (Fig. 1), the ammonia vapour (2) is separated from ammonia-water solution (1) by heating the solution in the generator; the ammonia vapour is condensed in a condenser, and the liquid ammonia (4) is expanded in an expansion valve. However, in the evaporator (5) the ammonia is evaporated by exchanging heat necessary for its evaporation and performing the "refrigerating effect". The ammonia, in the vapour state (6), is absorbed by the ammonia poor solution (10). The absorption reaction is exothermic and occurs in a vessel known as absorber, producing a solution rich in ammonia (ammonia-water, $\mathrm{NH}_{4} \mathrm{OH}$ ). The rich solution (7) is then pumped by the liquid pump (8), through a heat exchanger and into the generator (1), ending the cycle. The poor solution exiting the generator (3) passes through a heat exchanger, pre-heating the rich solution, passes through an expansion valve (entered at point 9) to equalise the pressure with the ammonia vapour coming from the evaporator (6) and enters the absorber (10).

\section{Mathematical modelling}

In this section, a novel mathematical modelling to calculate the entropy of ammonia-water mixture as a function of temperature, pressure, concentration, and other thermodynamic properties associated to absorption process, to support energy and exergy analysis of absorption refrigeration systems at liquid and vapour phases is presented.

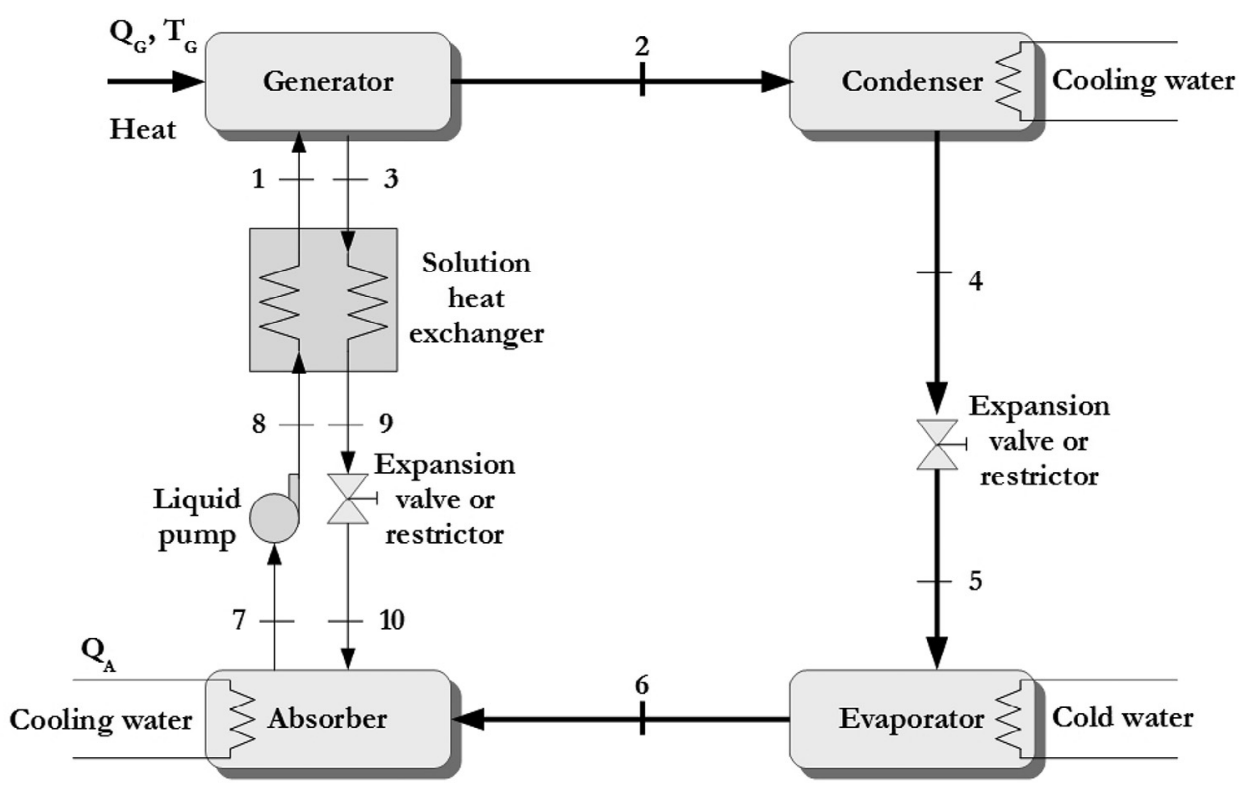

Fig. 1 - Basic ARS diagram (Zukowski, 1999). 


\subsection{Liquid phase}

\subsubsection{Excess enthalpy calculation method}

The excess enthalpy at certain pressure and temperature can be expressed by Eqs. (1) and (2).

$\mathrm{h}^{\mathrm{E}}=\mathrm{h}_{\text {MIXT.ACTUAL }}-\mathrm{h}_{\text {MIXT.IDEAL }}$

$\mathrm{h}_{\text {MIXT.IDEAL }}=\mathrm{x}_{\mathrm{i}} \mathrm{h}_{\mathrm{i}}+\mathrm{x}_{\mathrm{j}} \mathrm{h}_{\mathrm{j}}$

To obtain enthalpy values in liquid phase of ammoniawater mixture the enthalpy-concentration diagram was used (Costa, 1976) in case of graphical representation of enthalpies of solutions of different concentrations at constant temperature for different pressures. A corresponding temperature range between $-40{ }^{\circ} \mathrm{C}$ and $80^{\circ} \mathrm{C}$ was used for development of these calculations.

\subsubsection{Excess entropy calculation method}

Excess entropy is obtained by Eqs. (3) and (4) using excess enthalpy values and excess Gibbs free energy.

$\mathrm{S}^{\mathrm{E}}=\mathrm{S}_{\text {MIXT.ACTUAL }}-\mathrm{S}_{\text {MIXT.IDEAL }}$

$\mathrm{S}_{\text {MIXT.IDEAL }}=\mathrm{x}_{\mathrm{i}} \mathrm{s}_{\mathrm{i}}+\mathrm{x}_{\mathrm{j}} \mathrm{s}_{\mathrm{j}}-\mathrm{R}\left(\mathrm{x}_{\mathrm{i}} \ln \mathrm{x}_{\mathrm{i}}+\mathrm{x}_{\mathrm{j}} \ln \mathrm{x}_{\mathrm{j}}\right)$

The entropy values for components of ammonia-water mixture were obtained from reference tables (Reynolds, 1979) in the temperatures range corresponding to absorption refrigeration cycle considered in this work. Values obtained were subjected to a linear regression method using the REGRE software (Caceres-Munizaga et al., 1994), and later to compute $s_{i}$ and $s_{j}$ corresponding to entropy of ammonia and water in liquid phase of an ideal mixture. Determination of entropy evaluation of actual mixture was obtained by sum of excess entropy with entropy of ideal mixture.

The analysis of non-linear regression is an optimisation problem, in which a certain objective function should be minimised; the objective function is somewhat arbitrary, but must include experimental data of the proposed model. The REGRE program is based on the modified Marquardt method, which is an appropriate combination of local linearisation method and the steepest descent method. The objective function described in the program is:

$\mathrm{F}=\sum_{\mathrm{i}=1}^{\mathrm{n}}\left(\mathrm{M}_{\mathrm{EXP} .}-\mathrm{M}_{\mathrm{CALC} .}\right)_{\mathrm{i}}$

Absolute errors between property experimental values $\left(\mathrm{M}_{\mathrm{EXP}}\right)$ and values predicted by the model on study ( $\mathrm{M}_{\mathrm{CALC}}$.) were minimised. This calculation is based in subroutines of ChemCAD III program.

The program ChemCAD III (Chemstations, 1998) is a high level steady state process simulator and applicable to several industrial processes. It is similar to other commercial simulators, including a series of thermodynamic options for the most different applications where the simulator is designed.

The equations of state commonly used are Soave-RedlichKwong, Peng-Robinson, and Lee-Kesler; and among models used in the simulation to calculate the activity coefficient of a component in the liquid phase are: Wilson, NRTL, UNIQUAC, UNIFAC, Margules, Van Laar, and regular solution.

The program ChemCAD III was used in this work to determine the parameters $\Lambda_{12}$ and $\Lambda_{21}$ of Wilson equation through the model used for the calculation of parameters. Initially the program set temperature $(\mathrm{K})$, pressure (atm), and molar fraction (mol) for the respective units. These features were chosen for ammonia-water mixture, which was selected into software menu, even as the Wilson model, and then the linear regression is started. After these software configurations all desired parameters values were obtained.

\subsubsection{Actual entropy calculation method}

The objective of the development of this work is to determine the actual entropy of ammonia-water mixture. The actual entropy and excess entropy of mixture are presented by Eqs. (6) and (7).

$\mathrm{S}_{\text {MIST.ACTUAL }}=\mathrm{X}_{\mathrm{i}} \mathrm{S}_{\mathrm{i}}+\mathrm{x}_{\mathrm{j}} \mathrm{S}_{\mathrm{j}}-\mathrm{R}\left(\mathrm{x}_{\mathrm{i}} \ln \mathrm{x}_{\mathrm{i}}+\mathrm{x}_{\mathrm{j}} \ln \mathrm{x}_{\mathrm{j}}\right)+\mathrm{s}^{\mathrm{E}}$

$S^{E}=\frac{h^{E}-G^{E}}{T}$

Wilson's equation, which is based on molecular considerations, was used for determination of excess Gibbs free energy of a binary solution, Eq. (8) (Prausnitz et al., 1999).

$\frac{G^{E}}{R T}=-x_{i} \ln \left(x_{i}+\Lambda_{i j} x_{j}\right)-x_{j} \ln \left(x_{j}+\Lambda_{j i} x_{i}\right)$

According to Prausnitz et al. (1999), the excess Gibbs energy is defined with reference to an ideal solution in the sense of Raoult's law and Henry's law, also directly related to Wilson (1964).

Binary Wilson's equation parameters, $\Lambda_{\mathrm{ij}}$ and $\Lambda_{\mathrm{ji}}$, were determined by Eqs. (9)-(11).

$\Lambda_{\mathrm{ij}}=\frac{\mathrm{V}_{\mathrm{j}}(\mathrm{T})}{\mathrm{V}_{\mathrm{i}}(\mathrm{T})} \mathrm{e}^{\frac{\alpha}{\mathrm{RT}}}$

$\Lambda_{j \mathrm{i}}=\frac{\mathrm{V}_{\mathrm{i}}(\mathrm{T})}{\mathrm{V}_{\mathrm{j}}(\mathrm{T})} \mathrm{e}^{\frac{\beta}{\mathrm{RT}}}$

$\mathrm{V}=\frac{\mathrm{A}}{\mathrm{B}^{\left(1-\frac{\mathrm{T}}{\mathrm{T}_{\mathrm{c}}}\right)^{\frac{2}{7}}}}$

Wilson's equation can be used in here because the liquid phase of this system presents a completely miscible mixture (Prausnitz et al., 1999; Wilson, 1964).

Values of $\alpha$ and $\beta$ in Eqs. (9) and (10) were calculated by using the $\Lambda_{12}$ and $\Lambda_{21}$ factors determined by software ChemCAD III, from the data of ammonia-water mixture at temperatures from 0 to $80^{\circ} \mathrm{C}$, and represented as Eqs. (12) and (13).

$\alpha=\mathrm{a}_{\mathrm{i}}+\mathrm{a}_{\mathrm{j}} \mathrm{T}$

$\beta=b_{i}+b_{j} T$ 
In software ChemCAD III these parameters $\left(\Lambda_{12}\right.$ and $\left.\Lambda_{21}\right)$ are referred to as $\mathrm{A}_{12}$ and $\mathrm{A}_{21}$.

\section{Results and discussion}

\subsection{Results obtained for liquid phase}

The studies were based on the enthalpy vs. concentration diagram obtaining the enthalpy in the liquid phase corresponding at a temperature range from $80^{\circ} \mathrm{C}(353.15 \mathrm{~K})$ through $-40{ }^{\circ} \mathrm{C}(235.15 \mathrm{~K})$. The mixtures enthalpy values calculated for ammonia $\left(\mathrm{h}_{1 \mathrm{c}}\right)$ and water $\left(\mathrm{h}_{2 \mathrm{c}}\right)$ corresponding to the polynomial Eqs. (14) and (15) were obtained by using a non-linear regression program (REGRE) (Caceres-Munizaga et al., 1994).

$$
\begin{aligned}
\mathrm{h}_{1 \mathrm{c}}= & -1,015.41+6.24861 \cdot \mathrm{T}-0.009416381 \cdot \mathrm{T}^{2} \\
& +0.00001569906 \cdot \mathrm{T}^{3}
\end{aligned}
$$

$\mathrm{h}_{2 \mathrm{c}}=-994.168+2.776773 \cdot \mathrm{T}+0.004352178 \cdot \mathrm{T}^{2}$

$$
-0.000004393749 \cdot \mathrm{T}^{3}
$$

From Eqs. (14) and (15) calculated enthalpy values, the enthalpy of ideal mixture (ammonia-water) was obtained. The excess enthalpy was obtained by the difference between actual and ideal calculated mixture enthalpy.

The excess Gibbs energy was calculated using the Wilson model [Eq. (9)] for the binary components. The Wilson equation parameters were determined using the computer program ChemCAD III.

The excess entropy was obtained by the computed difference between the excess enthalpy and excess Gibbs energy with respect to temperature. Values of calculated entropies for ammonia $\left(\mathrm{s}_{1 \mathrm{c}}\right)$ and water $\left(\mathrm{s}_{2 \mathrm{c}}\right)$ mixtures were adjusted using the polynomial Eqs. (16) and (17).

$$
\begin{aligned}
\mathrm{S}_{1 \mathrm{c}}= & -6.71612+0.04869194 \cdot \mathrm{T}-0.000095628 \cdot \mathrm{T}^{2} \\
& +0.0000000910479 \cdot \mathrm{T}^{3}
\end{aligned}
$$

$$
\begin{aligned}
\mathrm{S}_{2 \mathrm{c}}= & -6.400273+0.33386 \cdot \mathrm{T}-0.00004291395 \cdot \mathrm{T}^{2} \\
& +0.00000002359528 \cdot \mathrm{T}^{3}
\end{aligned}
$$

The actual entropy was calculated by the sum of the excess entropy and ideal entropy, shown in Eq. (6).

The entropy vs. concentration thermodynamic diagram of ammonia in the liquid phase shows the pressure curves corresponding to $0.1 \mathrm{MPa}$ and $2 \mathrm{MPa}$ and temperature curves corresponding to a range of $0{ }^{\circ} \mathrm{C}(273.15 \mathrm{~K})$ to $190{ }^{\circ} \mathrm{C}(463.15 \mathrm{~K})$ (Fig. 2).

For constructing this thermodynamic diagram, real values of mixture property were considered. A spreadsheet of thermodynamic properties of excess, ideal and actual using the software MS-Excel@, was developed. The equations allow to obtain data on the properties from different values of concentration of ammonia present in the mixture $(0.05,0.2,0.4$, $0.6,0.8,1.0 \mathrm{~kg}$ of ammonia $\mathrm{kg}^{-1}$ of mixture).

These values were used because the mixture presents great variation, which does not permit to work with a continuous function.

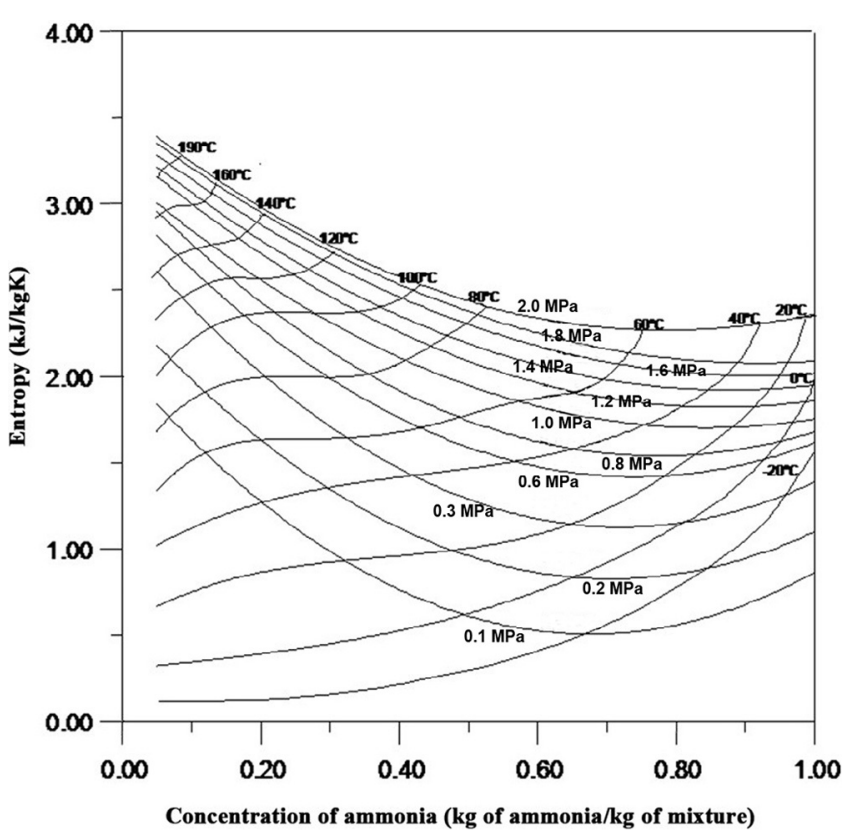

Fig. 2 - Diagram of entropy vs. concentration of ammonia (liquid phase of the mixture).

For the results of properties in excess (enthalpy, entropy and Gibbs free energy), a diagram to elucidate the behaviour of the ammonia-water mixture in the liquid phase, corresponding to a pressure of $0.1 \mathrm{MPa}(1 \mathrm{~atm})$ and temperature of $323 \mathrm{~K}\left(50^{\circ} \mathrm{C}\right)$ was plotted.

\subsection{Vapour phase}

\subsubsection{Equation of state for pure component}

The fundamental Gibbs free energy equation (G) of a pure component may be obtained from known relationships for volume and heat capacity as a function of temperature and pressure. According to Ibrahim and Klein (1993), the fundamental equation for Gibbs free energy can be expressed in integral form as Eq. (18):

$G=h_{0}-T s_{0}+\int_{T_{0}}^{T} C_{p} d T+\int_{P_{0}}^{P} V d P-T \int_{T_{0}}^{T}\left(\frac{C_{p}}{T}\right) d T$

where $h_{0}, s_{0}, T_{0}$, and $P_{0}$ correspond to specific enthalpy, specific entropy, temperature, and pressure of reference in the vapour phase. The reduced volume $\left(\mathrm{V}_{\mathrm{r}}\right)$ and specific heat capacity $\left(C_{P}\right)$ are correlated according to Eqs. (19) and (20).

$\mathrm{V}_{\mathrm{r}}^{\mathrm{g}}=\frac{\mathrm{RT}_{\mathrm{r}}}{\mathrm{P}_{\mathrm{r}}}+\mathrm{C}_{1}+\frac{\mathrm{C}_{2}}{\mathrm{~T}_{\mathrm{r}}^{3}}+\frac{\mathrm{C}_{3}}{\mathrm{~T}_{\mathrm{r}}^{11}}+\frac{\mathrm{C}_{4} \mathrm{P}_{\mathrm{r}}^{2}}{\mathrm{~T}_{\mathrm{r}}^{11}}$

$C p^{g, o}=D_{1}+D_{2} T_{r}+D_{3} T_{r}^{2}$

For vapour phase in mixtures system, the empirical relationship corresponding to Gibbs free energy can be expressed by substituting Eqs. (19) and (20) into Eq. (18). After integrations, intensive function of Gibbs free energy for pure ammonia and water in the vapour phase is related to Eq. (21). 


$$
\begin{aligned}
G_{r}^{g}= & h_{r, 0}^{g}-T_{r} S_{r, 0}^{g}+D_{1} T_{r}-D_{1} T_{r, 0}+\frac{D_{2} T_{r}^{2}}{2}-\frac{D_{2} T_{r, 0}^{2}}{2}+\frac{D_{3} T_{r}^{3}}{3}-\frac{D_{3} T_{r, 0}^{3}}{3} \\
& -D_{1} T_{r}\left(\ln T_{r}-\ln T_{r, 0}\right)-D_{2} T_{r}^{2}+D_{2} T_{r} T_{r, 0}-\frac{D_{3} T_{r}^{3}}{2}+\frac{D_{3} T_{r} T_{r, 0}^{2}}{2} \\
& +T_{r}\left(\ln P_{r}-\ln P_{r, 0}\right)+C_{1}\left(P_{r}-P_{r, 0}\right)+C_{2} \frac{P_{r}}{T_{r}^{3}}-\frac{4 C_{2} P_{r, 0}}{T_{r}^{3}}+\frac{3 C_{2} P_{r, 0} T_{r}}{T_{r, 0}^{4}} \\
& +\frac{C_{3} P_{r}}{T_{r}^{11}}-\frac{12 C_{3} P_{r, 0}}{T_{r, 0}^{11}}+\frac{11 C_{3} P_{r, 0} T_{r}}{T_{r, 0}^{12}}+\frac{C_{4} P_{r}^{3}}{3 T_{r}^{11}}-\frac{12 C_{4} P_{r, 0}^{3}}{3 T_{r, 0}^{11}}+\frac{11 C_{4} P_{r, 0}^{3} T_{r}}{3 T_{r, 0}^{12}}
\end{aligned}
$$

Eq. (22) is obtained by Eq. (21) differentiating with respect to the reduced temperature $\left(\mathrm{T}_{\mathrm{r}}\right)$.

$$
\begin{aligned}
\frac{\partial\left(\frac{\mathrm{G}_{\mathrm{r}}^{\mathrm{g}}}{\mathrm{T}_{\mathrm{r}}}\right)}{\partial \mathrm{T}_{\mathrm{r}}}= & -\mathrm{h}_{\mathrm{r}, 0}^{\mathrm{g}} \mathrm{T}_{\mathrm{r}}^{-2}+\mathrm{D}_{1} \mathrm{~T}_{\mathrm{r}, 0} \mathrm{~T}_{\mathrm{r}}^{-2}+\frac{\mathrm{D}_{2} \mathrm{~T}_{\mathrm{r}}}{2}+\frac{\mathrm{D}_{2} \mathrm{~T}_{\mathrm{r}, 0}^{2} \mathrm{~T}_{\mathrm{r}}^{-2}}{2}+\frac{2 \mathrm{D}_{3} \mathrm{~T}_{\mathrm{r}}}{3}+\frac{\mathrm{D}_{3} \mathrm{~T}_{\mathrm{r}, 0}^{3} \mathrm{~T}_{\mathrm{r}}^{-2}}{3} \\
& -\mathrm{D}_{1} \ln \left(\frac{1}{\mathrm{~T}_{\mathrm{r}}}\right)-\mathrm{D}_{2}-\mathrm{D}_{3} \mathrm{~T}_{\mathrm{r}}+\frac{\mathrm{D}_{3}}{2} \mathrm{~T}_{\mathrm{r}, 0}^{2} \mathrm{~T}_{\mathrm{r}}^{-2}-\mathrm{C}_{1}\left(\mathrm{P}_{\mathrm{r}}-\mathrm{P}_{\mathrm{r}, 0}\right) \mathrm{T}_{\mathrm{r}}^{-2} \\
& -4 \mathrm{C}_{2} \mathrm{P}_{\mathrm{r}} \mathrm{T}_{\mathrm{r}}^{-5}+16 \mathrm{C}_{2} \mathrm{P}_{\mathrm{r}, 0} \mathrm{~T}_{\mathrm{r}}^{-5}-12 \mathrm{C}_{3} \mathrm{P}_{\mathrm{r}} \mathrm{T}_{\mathrm{r}}^{-13}+\frac{12 \mathrm{C}_{3} \mathrm{P}_{\mathrm{r}, 0} \mathrm{~T}_{\mathrm{r}}^{-2}}{\mathrm{~T}_{\mathrm{r}, 0}^{11}} \\
& -4 \mathrm{C}_{4} \mathrm{P}_{\mathrm{r}}^{3} \mathrm{~T}_{\mathrm{r}}^{-13}+\frac{4 \mathrm{C}_{4} \mathrm{P}_{\mathrm{r}, 0}^{3} \mathrm{~T}_{\mathrm{r}}^{-2}}{\mathrm{~T}_{\mathrm{r}, 0}^{11}}
\end{aligned}
$$

In Eq. (21), the superscript $g$ corresponds to the vapour phase in the ideal gas state. The reduced thermodynamic properties are expressed with the subscript $r$, being presented by Eqs. (23)-(27).

$\mathrm{T}_{\mathrm{r}}=\frac{\mathrm{T}}{\mathrm{T}_{\mathrm{B}}}$

$\mathrm{P}_{\mathrm{r}}=\frac{\mathrm{P}}{\mathrm{P}_{\mathrm{B}}}$

$\mathrm{G}_{\mathrm{r}}=\frac{\mathrm{G}}{\mathrm{RT}_{\mathrm{B}}}$

$\mathrm{h}_{\mathrm{r}}=\frac{\mathrm{h}}{\mathrm{RT}_{\mathrm{B}}}$

$\mathrm{S}_{\mathrm{r}}=\frac{\mathrm{S}}{\mathrm{R}}$

The reference values of the reduced properties are $\mathrm{R}=8.314 \mathrm{~kJ} \mathrm{kmol}^{-1} \mathrm{~K}^{-1}, \mathrm{~T}_{\mathrm{B}}=100 \mathrm{~K}$, and $\mathrm{P}_{\mathrm{B}}=0.1 \mathrm{MPa}$.

In terms of reduced variables, Eqs. (26) and (27) can be written as Eqs. (28) and (29).

$h=-R_{B} T_{r}^{2}\left[\frac{\partial}{\partial T_{r}}\left(\frac{G_{r}}{T_{r}}\right)\right]_{P}$

$\mathrm{S}=-\mathrm{R}\left[\frac{\partial \mathrm{G}_{\mathrm{r}}}{\partial \mathrm{T}_{\mathrm{r}}}\right]_{\mathrm{P}}$

By inserting the term $\left[\frac{\partial}{\partial T_{r}}\left(\frac{G_{r}}{T_{r}}\right)\right]_{P}$ obtained in Eq. (22) in Eq. (28), the reduced enthalpy calculated in the vapour phase associated with the ammonia-water system was determined by Eq. (30).
Table 1 - Coefficients of pure components of the

ammonia-water mixture (Ziegler and Trepp, 1984).

\begin{tabular}{lll} 
Coefficient & \multicolumn{1}{c}{ Ammonia } & \multicolumn{1}{c}{ Water } \\
\hline $\mathrm{C}_{1}$ & $-1.049377 \times 10^{-2}$ & $2.136131 \times 10^{-2}$ \\
$\mathrm{C}_{2}$ & -8.288224 & $-3.169291 \times 10^{+1}$ \\
$\mathrm{C}_{3}$ & $-6.647257 \times 10^{+2}$ & $-4.634611 \times 10^{+4}$ \\
$\mathrm{C}_{4}$ & $-3.045352 \times 10^{+3}$ & 0.0000 \\
$\mathrm{D}_{1}$ & 3.673647 & 4.019170 \\
$\mathrm{D}_{2}$ & $9.989629 \times 10^{-2}$ & $-5.175550 \times 10^{-2}$ \\
$\mathrm{D}_{3}$ & $3.617622 \times 10^{-2}$ & $1.951939 \times 10^{-2}$ \\
$h_{r, 0}^{L}$ & 4.878573 & 21.821141 \\
$h_{r, 0}^{g}$ & 26.468873 & 60.965058 \\
$s_{r, 0}^{L}$ & 1.644773 & 5.733498 \\
$s_{r, 0}^{g}$ & 8.339026 & 13.453430 \\
$\mathrm{~T}_{r, 0}$ & 3.2252 & 5.0705 \\
$\mathrm{P}_{\mathrm{r}, 0}$ & 2.000 & 3.000 \\
\hline
\end{tabular}

$$
\begin{aligned}
h_{r}= & \frac{R T_{B} T_{r}^{2} D_{2}}{2}+\frac{2 R T_{B} T_{r}^{3} D_{3}}{3}-R T_{B} T_{r}^{2} D_{1} \ln \left(\frac{1}{T_{r}}\right)-R_{B} T_{\mathrm{r}}^{2} D_{2} \\
& -R_{B} T_{r}^{3} D_{3}-4 R T_{B} C_{2} P_{r} T_{r}^{-3}+16 R T_{B} C_{2} P_{r, 0} T_{r}^{-3}-12 R_{B} C_{B} P_{r} T_{r}^{-11} \\
& -4 R T_{B} C_{4} P_{r}^{3} T_{r}^{-11}
\end{aligned}
$$

To calculate the reduced entropy in the vapour phase, the term $\left[\frac{\partial G_{\mathrm{r}}}{\partial \mathrm{T}_{\mathrm{r}}}\right]_{\mathrm{P}}$ based on Eq. (21) was used, which provides Eq. (31).

$$
\begin{aligned}
& \mathrm{S}_{\mathrm{r}}=\mathrm{Rs}_{\mathrm{r}, 0}^{\mathrm{g}}-\mathrm{RD}_{1}-\mathrm{RD}_{2} \mathrm{~T}_{\mathrm{r}}-\mathrm{RD}_{3} \mathrm{~T}_{\mathrm{r}}^{2}+\mathrm{RD}_{1} \ln \left(\frac{1}{\mathrm{~T}_{\mathrm{r}}}\right)+2 \mathrm{RD}_{2} \mathrm{~T}_{\mathrm{r}}-\mathrm{RD}_{2} \mathrm{~T}_{\mathrm{r}, 0} \\
& +\frac{3 R D_{3} T_{r}^{2}}{2}-\frac{R D_{3} T_{r, 0}^{2}}{2}-R \ln \left(\frac{P_{r}}{P_{r, 0}}\right)+3 R C_{2} P_{r} T_{r}^{-2} \\
& -12 R C_{2} P_{r, 0} T_{r}^{-4}-\frac{3 R C_{2} P_{r, 0}}{T_{r, 0}^{4}}+11 R C_{3} P_{r} T_{r}^{-12}-\frac{11 R C_{3} P_{r, 0}}{T_{r, 0}^{12}} \\
& +\frac{11 R C_{4} \mathrm{P}_{\mathrm{r}}^{3} \mathrm{~T}_{\mathrm{r}}^{-12}}{3}-\frac{11 \mathrm{RC}_{4} \mathrm{P}_{\mathrm{r}, 0}^{3}}{3 \mathrm{~T}_{\mathrm{r}, 0}^{12}}
\end{aligned}
$$

4.2.2. The entropy equation of mixtures in vapour phase The ammonia-water mixture in the vapour phase is assumed to have an ideal solution behaviour. The entropy of mixture in the vapour phase is represented by Eq. (32) (Xu and Yogi Goswami, 1999).

$\mathrm{S}_{\text {MIXT. }}^{\mathrm{g}}=\mathrm{X}_{\mathrm{g}} \mathrm{S}_{\mathrm{a}}^{\mathrm{g}}+\left(1-\mathrm{X}_{\mathrm{g}}\right) \mathrm{S}_{\mathrm{W}}^{\mathrm{g}}+\mathrm{S}_{\mathrm{MIXT}}$

$\mathrm{S}_{\mathrm{MIXT} .}=-\mathrm{R}\{\mathrm{xLn}(\mathrm{x})+(1-\mathrm{x}) \operatorname{Ln}(1-\mathrm{x})\}$

The coefficients values for Eqs. (21) and (31) are presented in Table 1.

\subsubsection{Results obtained for vapour phase}

The fundamental Gibbs free energy equation was used to develop the mathematical model relevant for calculation of thermodynamic properties of the vapour phase, such as specific enthalpy, specific entropy, and specific entropy of mixing involved in the cooling system by water-ammonia absorption.

The Gibbs free energy equation, given for the pure component, may be derived from known values of volume and heat capacity as a function of temperature and pressure relation- 

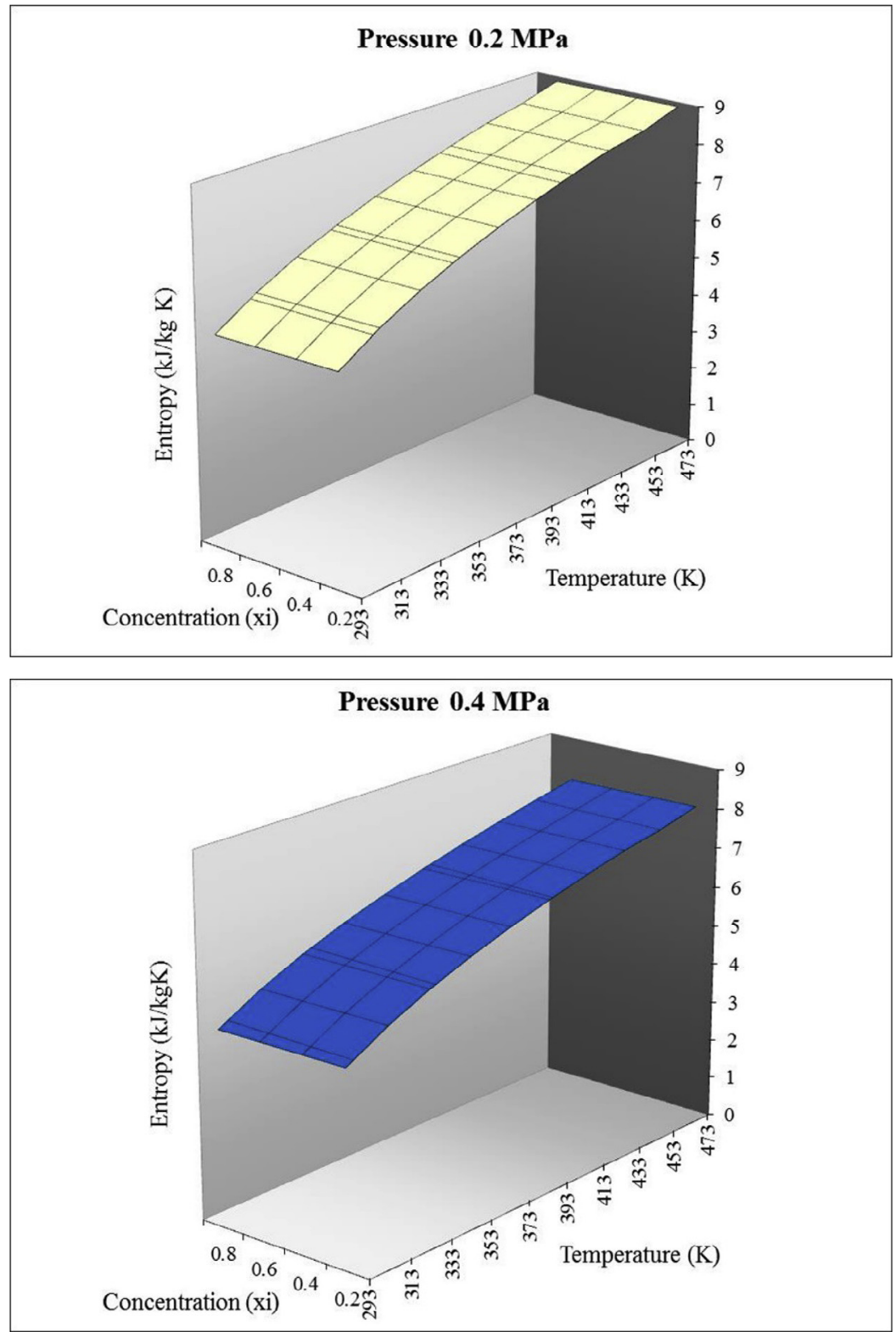

Fig. 3 - Entropy vs. ammonia concentration diagram for pressure ranges from 0.2 to $0.4 \mathrm{MPa}$.

ships. In order to determine the mixture entropy in the vapour phase, reduced thermodynamic properties presented in description of this section was used, as well as specific coefficients for pure components, resulting in the development of these calculations.

For the calculations associated with vapour phase, thermodynamic properties of ammonia-water mixture were related to the equation of state proposed by Ziegler and Trepp (1984), and subsequently, mathematical models were developed to determine the calculations of the pure components and the mixture belonging to vapour phase.

Entropy values of the mixture in the vapour phase were considered for plotting thermodynamic diagrams, also drawing at the same time a spreadsheet of thermodynamic properties using the software MS-Excel@.
The equations developed provided data on the properties for different values of ammonia concentration in the mixture $\left(0.1,0.2,0.4,0.6,0.8 \mathrm{~kg}\right.$ of ammonia $\mathrm{kg}^{-1}$ of mixture), considering a temperature range from $20^{\circ} \mathrm{C}(293.15 \mathrm{~K})$ through 200 ${ }^{\circ} \mathrm{C}(473.15 \mathrm{~K})$ and pressure from 0.1 through $2.0 \mathrm{MPa}$, shown in Figs. 3-7 that present two graphical compounds for each one, which are a comparison between two specific cases, such as in Fig. 3, presented concentration for $0.2 \mathrm{MPa}$ and for $0.4 \mathrm{MPa}$, and so on.

The entropy vs. ammonia concentration diagram allows for the study of mixture of ammonia and water for an absorption refrigeration system through simulation and optimisation of value ranges presented.

Data obtained by means of the proposed mathematical model underwent adjustments essential to plot these 

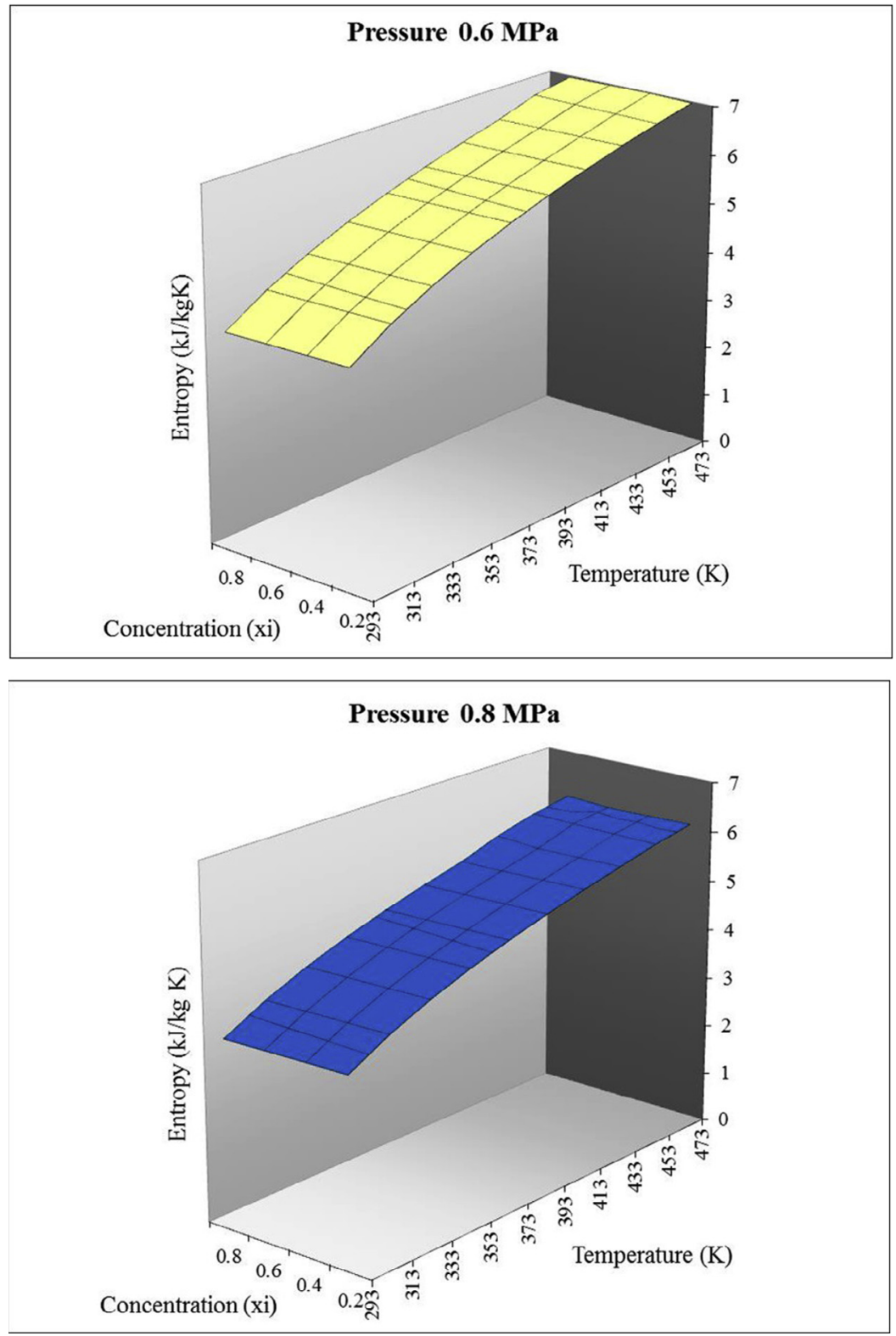

Fig. 4 - Entropy vs. ammonia concentration diagram for pressures of $0.6 \mathrm{MPa}$ and $0.8 \mathrm{MPa}$.

diagrams in the vapour phase, due to the difficulty of standardising some parameters involved in this system.

To compare this work with data reported by Rizvi and Heldemann (1987) it was necessary to adjust some points, thus assisting the preparation of diagrams pressure vs. concentration of ammonia; however, there was a good accuracy of these data, contributing to the analysis of refrigeration systems.

In current literature, pressure is often used in bar and temperature in Kelvin, so that it makes no sense to use concentration values higher than those used in this literature.

It should be emphasised that the temperature range chosen to develop this work is from $-40^{\circ} \mathrm{C}(233 \mathrm{~K})$ through $80^{\circ} \mathrm{C}(353 \mathrm{~K})$, a rather restricted range as compared to data reported in the literature, where ranges of pressure and temperature vary widely for the determination of thermodynamic properties associated with the cooling system by water-ammonia absorption.
Some data from this study, relating the pressure vs. ammonia concentration, were compared with results presented by Rizvi and Heldemann (1987) who studied the ammoniawater system for a wide range of temperatures corresponding to Figs. 8-10.

A work associated with the study of isothermal data from vapour-liquid equilibrium for ammonia-water system at temperatures ranging 306-618 $\mathrm{K}$ and pressures up to $22 \mathrm{MPa}$ was developed in Rizvi and Heldemann (1987). Figs. 8-10 compare isothermal data from Rizvi and Heldemann (1987) with results of this work near the critical temperature of ammonia.

In the study of the vapour-liquid equilibrium, the ammoniawater system becomes complex to obtain the exact amount related to the composition of the vapour phase. The uncertainty of the composition of this water in vapour phase becomes a difficult problem to solve for studies associated with the 

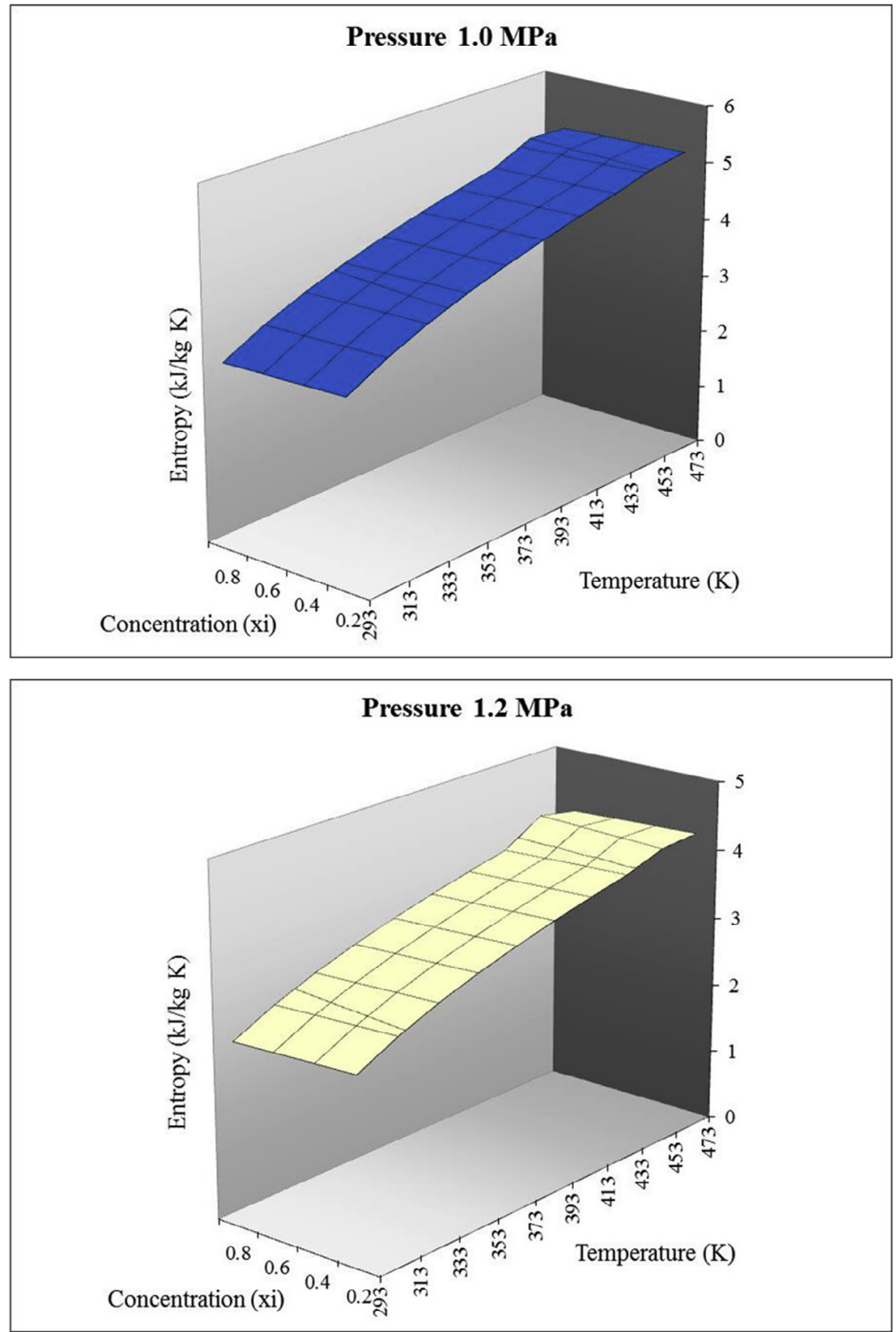

Fig. 5 - Entropy vs. ammonia concentration diagram for pressure ranges from 1.0 to $1.2 \mathrm{MPa}$.

vapour-liquid equilibrium, and some data available in the literature on this subject are referred to as inconsistent.

The data calculated in this work showed good correlation with the data of Rizvi and Heldemann (1987); however, they were obtained at a temperature about $2^{\circ} \mathrm{C}$ below the critical temperature of ammonia, being predicted that the results of the work of Rizvi and Heldemann (1987) reported temperature values exceeding the results of this work, even though the general trend of the data as a function of concentration is similar.

\section{Conclusions}

The present study shows the new three-dimensional diagrams of entropy, as function of concentration of $\mathrm{NH}_{3}$, pressure, and temperature. This sort of diagram permits exergy analysis in absorption refrigeration system applying mixtures of ammonia and water and it can be used to help many scientists working on the exergetic optimisation of designs and analysis. In general, engineers use this type of studies.

In the current Brazilian energy context and several developing countries, the use of absorption thermal machines appears to be a promising option. Cooling systems represent the best alternative to produce cold in regions where there is little distribution of electrical power, because they are powered directly through the burning of biogas (or other fuel) as a heat source or use of residual heat of co-generation systems. In the energy landscape scenarios, the use of absorption technology can be more interesting than compression refrigeration systems. 

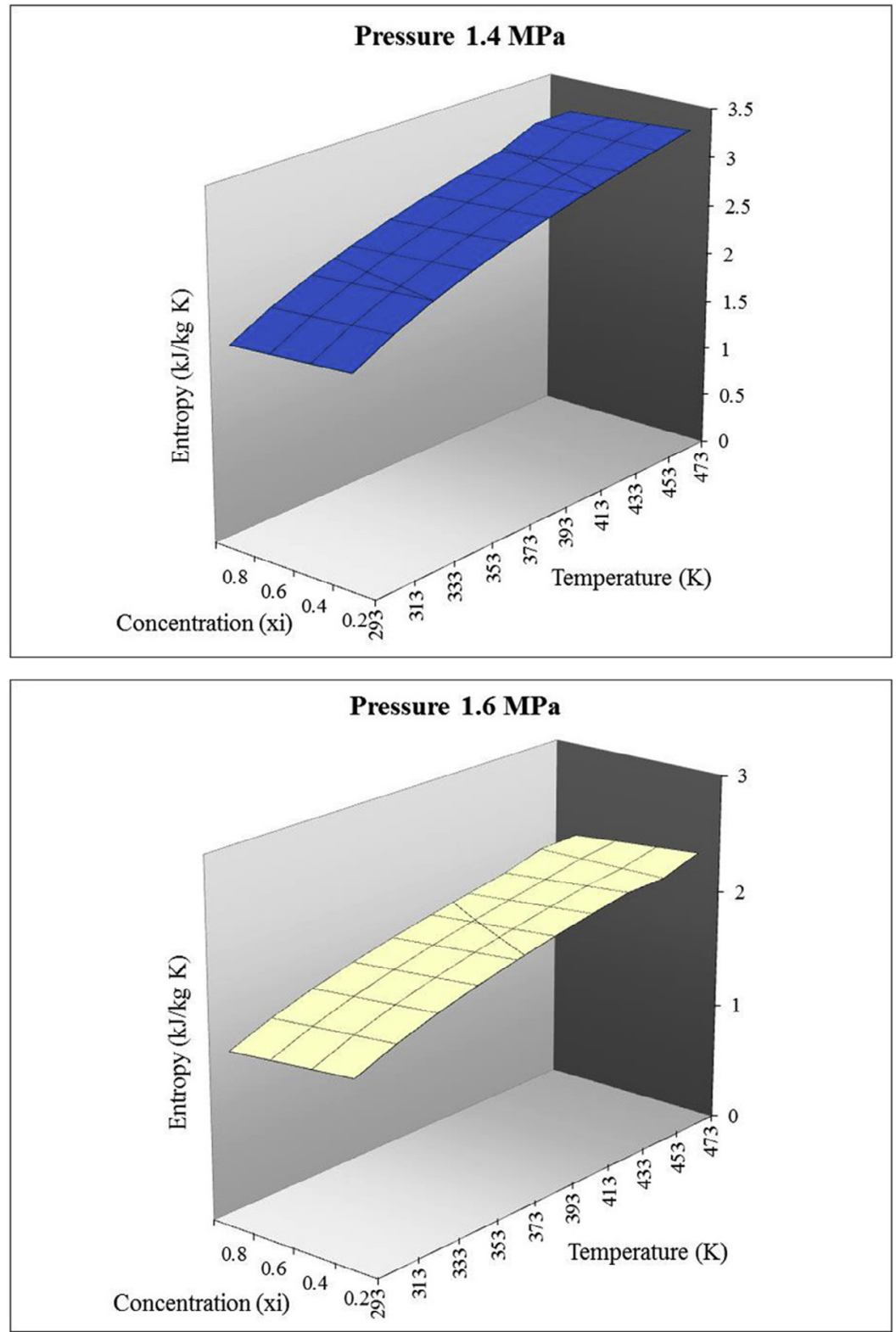

Fig. 6 - Entropy vs. ammonia concentration diagram for pressure ranges from 1.4 to $1.6 \mathrm{MPa}$.

The evaluation of thermodynamic properties in this work was discretised by formulating appropriate equations for each type of substance (ammonia-water). However, thermodynamic properties of mixtures can be determined based on data from simple substances and mixing laws, or from an equation of state that considers the mixture concentration. The consistency of the experimental data indicates the most suitable method to be used in entropy calculation. Several equations of state are discussed in the literature; however, due to their development complexity, they are not used to determine the thermodynamic properties of the mixture.

During the development of this work, thermodynamic properties of liquid phase and vapour associated with ammoniawater mixture of absorption refrigeration systems were studied. In the liquid phase of ammonia-water mixture the Wilson equation suitable for binary systems was used, whereas the parameters belonging to this mathematical model were determined by the software ChemCAD III. Since used relationships between the properties of mixtures made by Reynolds (1979) were used, adjustment points for making some of the entropy vs. concentration diagram is justified, and due to the mathematical model implemented, the curves originating in this diagram are not started from zero concentration point.

For the vapour phase of the mixture ammonia-water data adjustment, it was necessary to obtain the ordering of points between the working temperatures, making three-dimensional diagrams of entropy vs. concentration. In these threedimensional diagrams for the vapour phase, it was observed that with increasing pressure there occurred a decrease in 

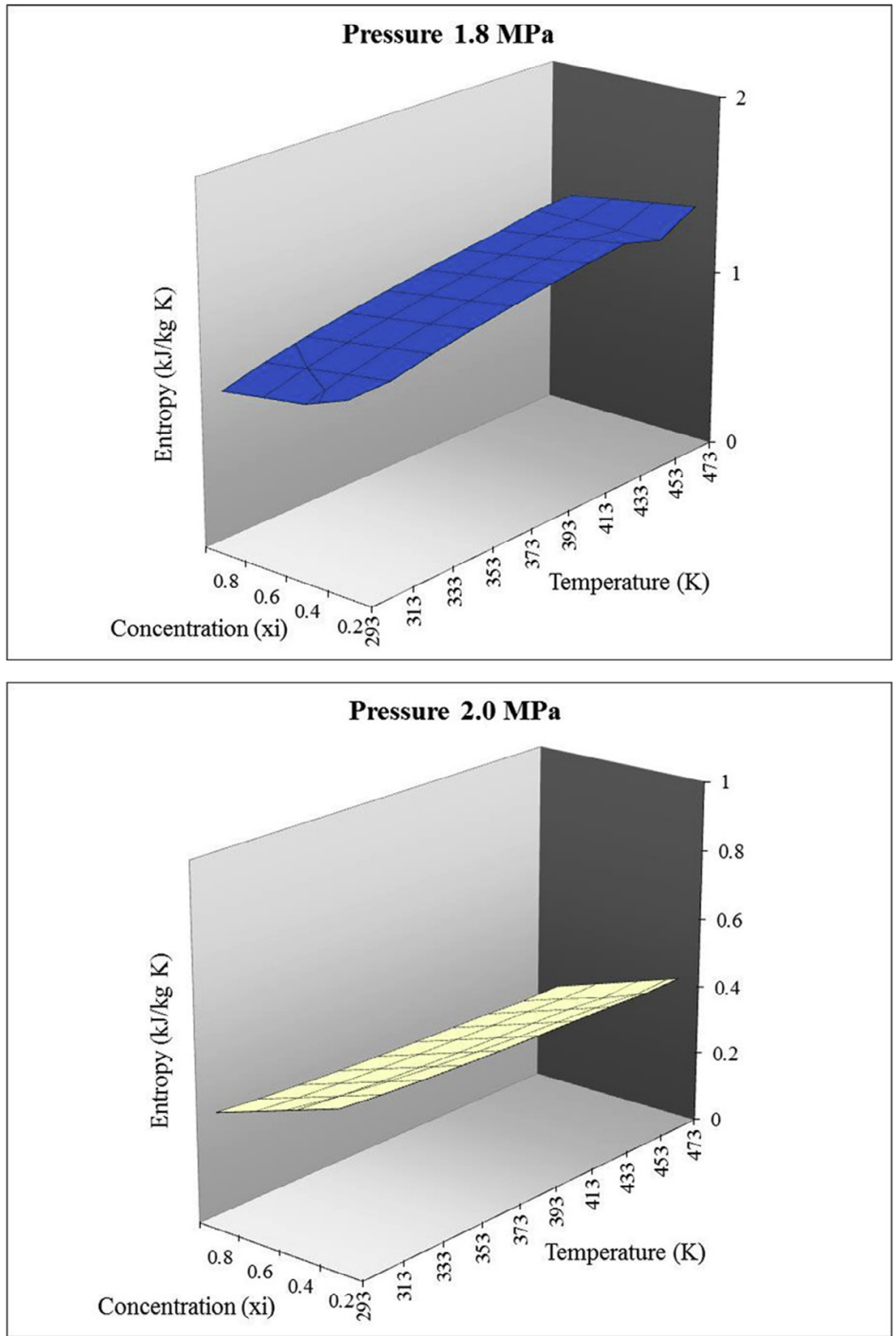

Fig. 7 - Entropy vs. ammonia concentration diagram for pressure ranges from 1.8 to $2.0 \mathrm{MPa}$.

entropy value associated with the cooling system by absorbing the mixture.

The scientific literature presents discussion of the ammoniawater system associated with the difficulty of determining the concentration in the vapour phase, due to the uncertainty of the composition of water present at this stage, making the data available inconsistent.

This paper presents some comparative data with other studies; however, it is necessary to emphasise the difficulty of comparison, since the related scientific papers present a wide range of pressure and temperature associated to ammoniawater mixture, making it impossible in most cases to compare other studies with this work that was developed for a narrow range of temperature and pressure with the application of absorption refrigeration systems.
However, data of certain thermodynamic properties show good accuracy and can contribute to the exergy and thermo-economic analysis of absorption refrigeration systems.

\section{Acknowledgments}

Dr. Jose Luz Silveira thanks his "Productivity Scholarship in Research," supported by the Brazilian National Council for Scientific and Technological Development (CNPq) (303295/ 2014-7). Dr. Giorgio Eugenio Oscare Giacaglia thanks his Visiting Professor Scholarship provided by the University of Taubate (UNITAU Ordinance No. 448/2016). 


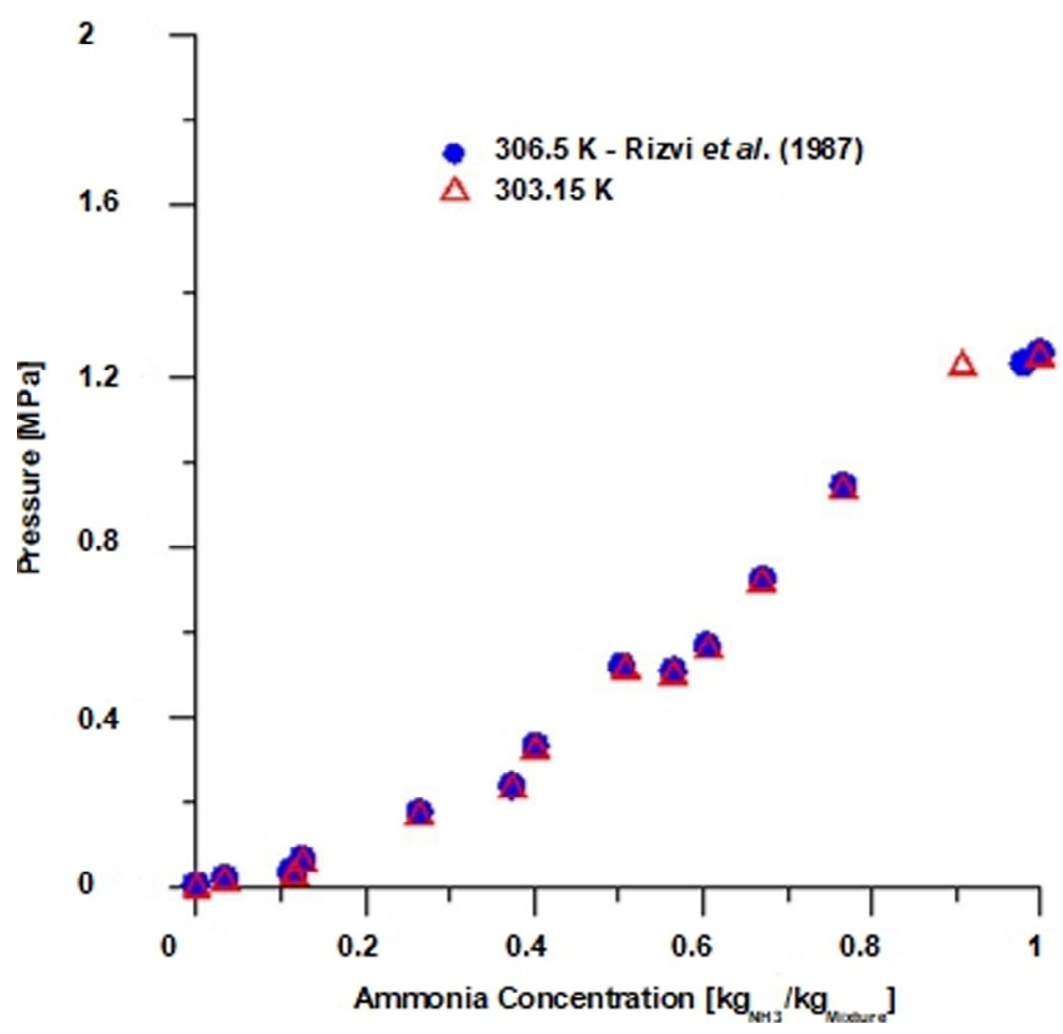

Fig. 8 - Phase diagram for the critical point of the ammonia corresponding to temperature of $306.5 \mathrm{~K}$.

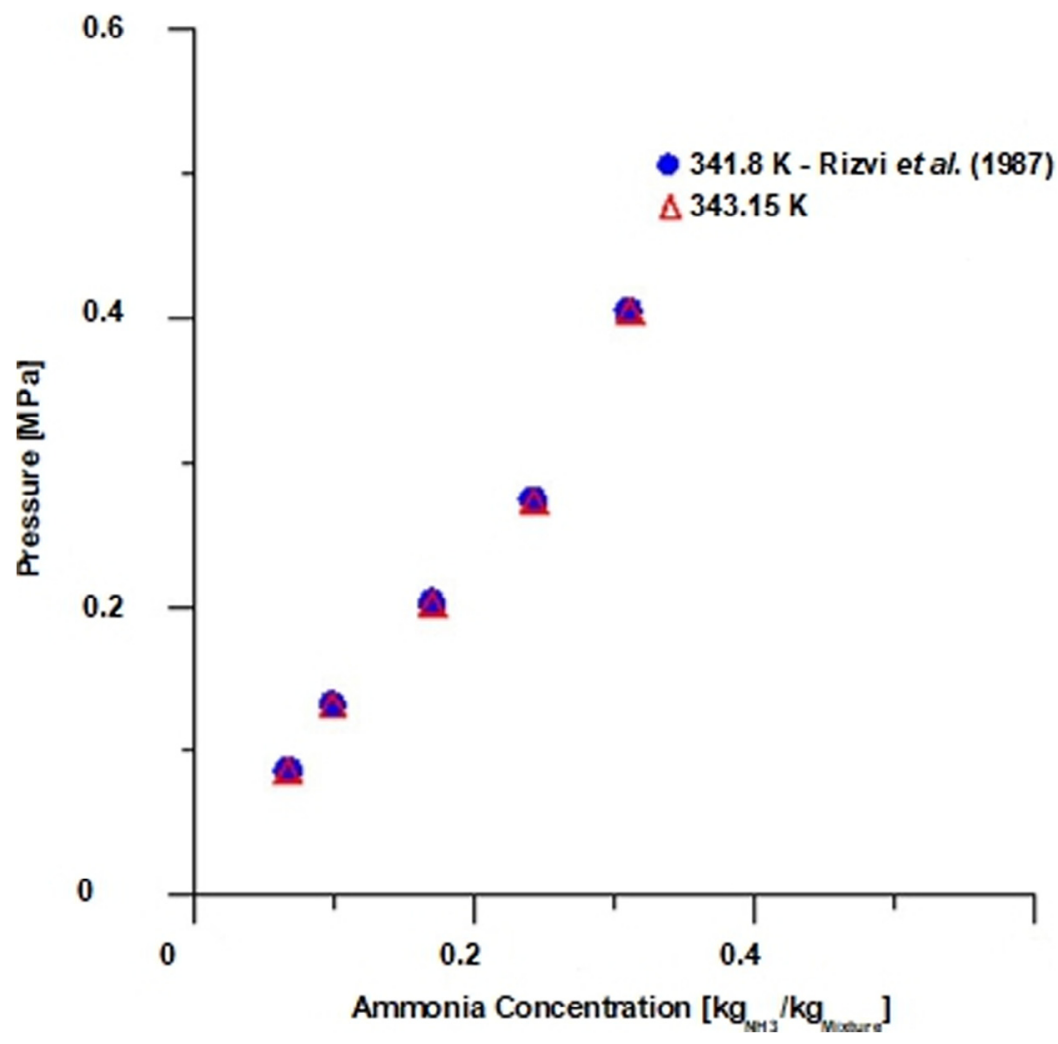

Fig. 9 - Phase diagram for the critical point of the ammonia corresponding to temperature of $341.8 \mathrm{~K}$. 


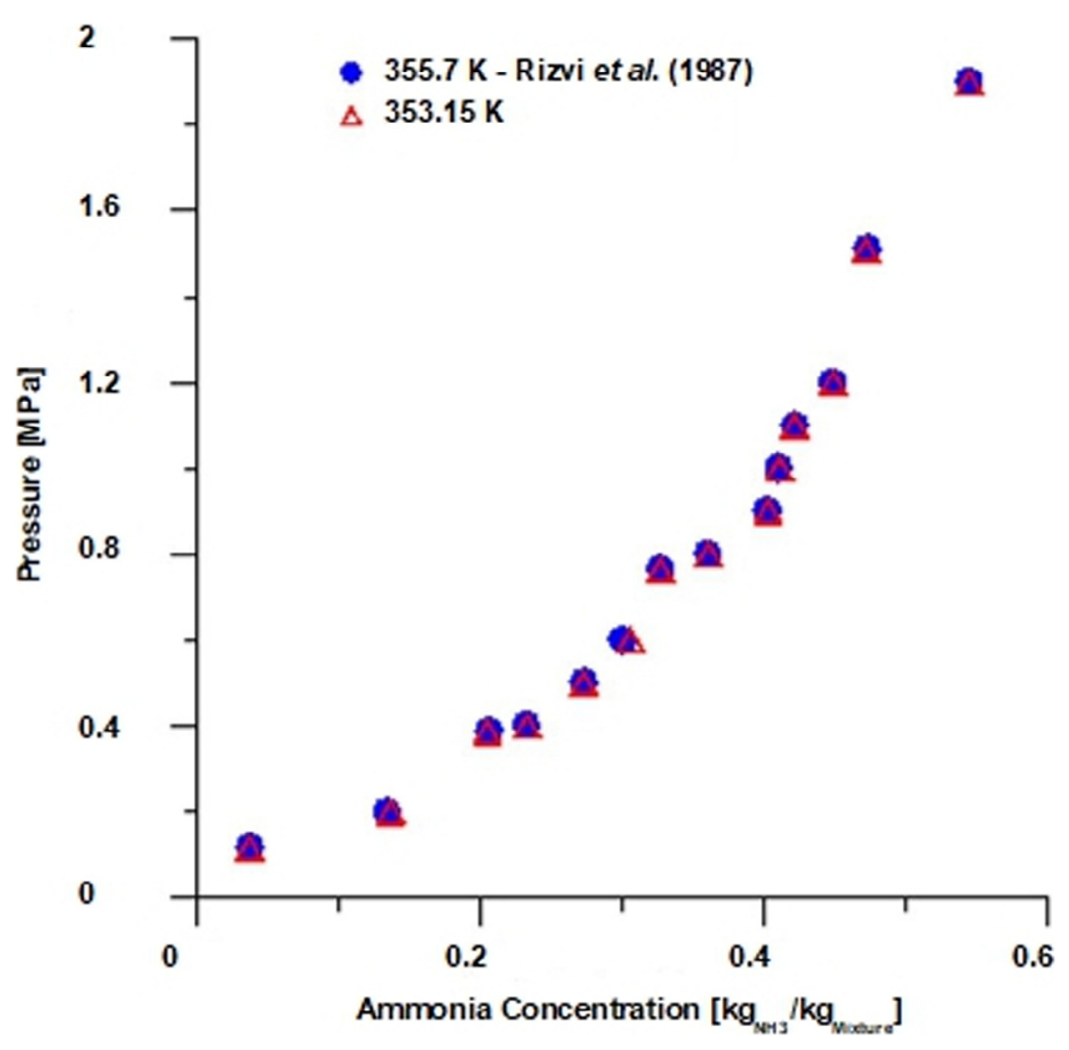

Fig. 10 - Phase diagram for the critical point of the ammonia corresponding to temperature of $355.7 \mathrm{~K}$.

\section{REFERENCES}

Akasaka, R., 2009. A rigorous calculation of the critical point from the fundamental equation of state for the water + ammonia mixture. Int. J. Refrigeration 32 (1), 95-101.

Alefeld, G., Radermacher, R., 1994. Heat Conversion System. CRC Press, Boca Raton.

Caceres-Munizaga, L.M., Valderrama, J.O., Goio, M., 1994. Computational program for non-linear regression of data at food sector. Alimentacion, Equipos y Tecnologia 13 (8), 105-110, (in Spanish).

Chemstations. ChemCAD 5.0: Process Flowsheet Simulator. Houston: Chemstations, 1998.

Costa, E.C., 1976. Industrial Physics - Refrigeration, vol. II. Editora Meridional EMMA, Porto Alegre.

Edison, T.A., Sengers, J.V., 1999. Thermodynamic properties of ammonia in the critical region. Int. J. Refrigeration 22 (5), 365-378.

Ibrahim, O.M., Klein, S.A., 1993. Thermodynamic properties of ammonia-water mixtures. ASHRAE Trans. Symposia 99, 1495-1502.

Mejbri, K., Bellagi, A., 2006. Modelling of the thermodynamic properties of the water-ammonia mixture by three different approaches. Int. J. Refrigeration 29 (2), 211-218.

Minea, V., Chiriac, F., 2006. Hybrid absorption heat pump with ammonia-water mixture - Some design guidelines and district heating application. Int. J. Refrigeration 29 (7), 1080-1091.

Patek, J., Klomfar, J., 1995. Simple functions for fast calculations of selected thermodynamic properties of the ammonia-water system. Int. J. Refrigeration 18 (4), 228-234.
Prausnitz, J.M., Lichtenthaler, R.N., Azevedo, E.G., 1999. Molecular Thermodynamics of Fluid-Phase Equilibria, third ed. PrenticeHall, Upper Saddle River, NJ.

Reynolds, W.C. Graphs, tables and computational equations for forty substances. Thermodynamic Properties in SI. Department of Mechanical Engineering - Stanford University, 1979.

Rizvi, S.S.H., Heldemann, R.A., 1987. Vapor-liquid equilibria in the ammonia-water system. J. Chem. Eng. Data 32, 183-191.

Seyfouri, Z., Ameri, M., 2012. Analysis of integrated compressionabsorption refrigeration systems powered by a micro-turbine. Int. J. Refrigeration 35 (6), 1639-1646.

Silva, A. Energy Evaluation of an Absorption $\left(\mathrm{H}_{2} \mathrm{O}-\mathrm{NH}_{3}\right)$ Facility for Ice Production from Process Vapour. M.Sc. thesis (Mechanical Engineering). Faculty of Mechanical Engineering, University of Campinas, Campinas, SP, Brazil, 1994.

Thorin, E., Dejfors, C., Svedberg, G., 1998. Thermodynamic properties of ammonia-water mixtures for power cycles. Int. J. Thermophys. 19 (2), 501-510.

Vasquez Padilla, R., Demirkaya, G., Yogi Goswami, D., Stefanakos, E., Rahman, M.M., 2010. Analysis of power and cooling cogeneration using ammonia-water mixture. Energy 35 (12), 4649-4657.

Wilson, G.M., 1964. Vapor-liquid equilibrium. XI. A new expression for the excess free energy of mixing. J. Am. Chem. Soc. 86 (2), 127-130. doi:10.1021/ja01056a002.

Xu, F., Yogi Goswami, D., 1999. Thermodynamic properties of ammonia-water mixtures for power-cycle applications. Energy 24 (6), 525-536.

Ziegler, B., Trepp, C., 1984. Equation of state for ammonia-water mixtures. Int. J. Refrigeration 7 (2), 101-106.

Zukowski, J.C., Jr. Sensitive Analysis of an Absorption Refrigeration System $\mathrm{H}_{2} \mathrm{O}-\mathrm{NH}_{3}$. Ph.D. dissertation (Mechanical Engineering). Faculty of Mechanical Engineering, University of Campinas, Campinas, SP, Brazil, 1999. 